\title{
COMPACTAÇÃO DE UM SOLO DE USO FLORESTAL SUBMETIDO AO TRÁFEGO DE ARRASTE DE MADEIRA ${ }^{1}$
}

\author{
Sebastião Eudes Lopes ${ }^{2}$, Haroldo Carlos Fernandes ${ }^{3}$, Luciano Baião Vieira ${ }^{3}$, Carlos Cardoso Machado ${ }^{4}$ e \\ Paula Cristina Natalino Rinaldi ${ }^{5}$
}

\begin{abstract}
RESUMO - Este trabalho teve como principal objetivo a avaliação dos níveis de compactação de um Latossolo Vermelho-Amarelo, de uso florestal, submetido ao tráfego comparativo entre duas versões de máquina de arraste de madeira, sobre pneus e esteiras, tendo em vista a escassez de informações sobre o tema e, ainda, considerando que o tráfego de máquinas habitualmente resulta em impactos no ecossistema, influenciando a qualidade dos recursos hídricos, a compactação do solo e a produtividade da floresta. As propriedades físicas do solo avaliadas foram: densidade, porosidade total e resistência mecânica do solo à penetração. O delineamento experimental empregado foi um esquema fatorial $2 \times 3 \times 3$, ou seja, duas versões de máquina empregadas em três condições de operação, discutidas em relação à testemunha sem tráfego e em três profundidades, tendo quatro repetições. Foi também aplicado o teste de interações para avaliar o efeito das duas versões do trator arrastador em relação ao número de percursos das máquinas. As médias foram comparadas pelo teste de Dunnet a 5\% de significância. A análise dos resultados obtidos apontou que, na faixa de profundidade entre 0 e $15 \mathrm{~cm}$, o trator arrastador sobre pneus, trafegando com carregamento de madeira em um ou dois percursos, provocou efeitos na compactação do solo. Nas mesmas condições, o tráfego do trator arrastador sobre esteiras, em dois percursos, produziu efeito análogo. Nas profundidades entre 15 e $50 \mathrm{~cm}$, somente dois percursos sobre pneus produziram alteração na compactação do solo.
\end{abstract}

Palavras-chave: Máquinas florestais, danos no solo e arraste de madeira.

\section{EVALUATION OF COMPACTION OF A FOREST SOIL SUBJECTED TO SKIDDER TRAFFIC}

\begin{abstract}
The objective of this research was to evaluate compaction of a Red-Yellow Latosol subjected to forestry traffic including two types of skidder: a wheeled-clambunk skidder and a tracked one. This study tries to remedy the lack of information on this subject, considering that mechanized traffic can result in several impacts on the environment. These impacts are related to soil compaction and water resources quality, resulting in reduction of forestry productivity. The soil physical parameters analysed were: soil dry bulk density, total porosity and soil penetrometer resistance. A $2 \times 3 \times 3$ factorial statistical design was used, including type of skidder, pattern operation and soil depth, using the Dunnet test at $5 \%$ significance level. The statistical analysis included the test of interaction between types of machines and the number of machine travels. Results showed that the loaded wheeled-clambunk skidder traveling once or twice caused effects of compaction on soil up to $15 \mathrm{~cm}$ depth. In the same condition, the tracked-skidder traveling twice also produced significant effect on soil compaction. In the 15-50 cm depth, only two travels of the wheeled-clambunk skidder caused soil compaction.
\end{abstract}

Keywords: Forest machines, damages in the soil and drag of wood.

\footnotetext{
${ }^{1}$ Recebido em 14.07.2004 e aceito para publicação em 05.04.2006.

${ }^{2}$ Programa de Pós-Graduação em Mecanização Agrícola da UFV, 36570-000 Viçosa-MG. E-mail: <sebastiaoeudes@ bol.com.br>.

${ }^{3}$ Departamento de Engenharia Agrícola da UFV.

${ }^{4}$ Departamento de Engenharia Florestal da UFV.

${ }^{5}$ Engenheira Agrícola.
} 


\section{INTRODUÇÃO}

O aumento significativo do uso de máquinas na produção agrícola e florestal trouxe vários problemas de ordem ambiental nos recursos hídricos e edáficos. As normas sobre a preservação dos recursos naturais estão obrigando as empresas do setor a manifestar interesses na identificação, quantificação e minimização dos efeitos de suas atividades sobre o meio ambiente, ou seja, elas terão que conduzir suas atividades de maneira condizente com o desenvolvimento florestal sustentável.

As operações mecanizadas de colheita florestal se intensificaram no início da década de 1990. Desde então, os sistemas de colheita florestal têm levado o solo a um processo acelerado de degradação, principalmente devido ao aumento do tráfego de máquinas, resultando em desequilíbrio de suas características físicas, químicas e biológicas, afetando progressivamente o seu potencial produtivo (DIAS JÚNIOR, 1999).

A compactação do solo pode ser definida como a ação mecânica por meio da qual se impõe ao solo redução de seu índice de porosidade, que pode ser definido como a relação entre o volume de vazios e o volume de sólidos (CAMARGO, 1983; SEIXAS, 1988). Os espaços porosos perdidos com o efeito da compactação são, na maioria, macroporos, que são importantes na movimentação de água e ar pelo solo.

A compactação é o aumento da densidade do solo em função dos arranjamentos das partículas primárias (argila, silte e areia). Quando o solo é submetido a um esforço cortante e, ou, de pressão, há redução no espaço poroso, aumentando sua densidade. Normalmente, os solos formados por partículas pequenas e de diferentes tamanhos são mais facilmente compactados, porque as partículas pequenas podem ser encaixadas nos espaços formados entre partículas maiores, formando camadas de impedimento com baixa macroporosidade (CAMARGO, 1983).

O comportamento do solo, com relação à compactação em decorrência do tráfego de máquinas, vem sendo estudado com freqüência no setor agrícola, porém são poucas as pesquisas que tratam desse assunto no setor florestal. Os danos causados pela compactação em solos de uso florestal diferem daqueles dos solos de uso agrícola devido a espécie, tamanho, ciclos das culturas cultivadas e máquinas utilizadas (GREACEN e SANDS, 1980). Esses autores relataram que os pesos das árvores e das máquinas empregadas no processo de colheita contribuem para o aumento da compactação do solo.

As características físicas e químicas do solo são diretamente afetadas pelo tipo de manejo a que é submetido. Kondo e Dias Júnior (1999) consideraram que o sistema de manejo do solo altera as propriedades físicas e mecânicas do solo com diferentes níveis de compactação, em função do teor de água, das diferentes classes de solos e da época de realização das operações mecanizadas. O tráfego de veículos pesados modifica a estrutura do solo, causando rompimento de suas resistências naturais - que se encontram interligadas por forças de atração e repulsão - alterando o fluxo de água no solo, reduzindo a produtividade da floresta e aumentando os níveis de erosão, já que geralmente reduz a taxa de infiltração, aumentando o escoamento superficial, uma vez que a velocidade da água no perfil do solo depende do tamanho dos poros (SEIXAS, 2000).

Estudando a compactação do solo causada por tráfego de máquina com base na variação da sua densidade, Hassan e Sirois (1985) constataram aumento significativo a partir de $10 \mathrm{~cm}$ de profundidade, afirmando que a compactação se deveu às cargas aplicadas pelos rodados dos equipamentos de colheita e arraste de madeira.

O efeito da compactação no desenvolvimento das plantas é percebido quando a raiz encontra resistência mecânica ao seu crescimento. Segundo Camargo (1983), esse impedimento ocorre quando o diâmetro da raiz é superior ao do poro no solo; se a raiz não romper esse impedimento, o sistema radicular da planta ficará denso e raso.

Estudos de compactação do solo realizados por Greacen e Sands (1980) em operações florestais mecanizadas na Austrália detectaram pressão entre $85 \mathrm{kPa}$ e $100 \mathrm{kPa}$ para um skidder. As medições foram realizadas, dividindo-se a massa total da máquina pela área de contato com o solo; e as interferências dinâmicas causadas pelo movimento da máquina e as geradas pelo peso da madeira não foram desprezadas. Os autores afirmaram que a carga dinâmica, a pressão interna dos pneus e as múltiplas passadas afetam a densidade do solo, a qual varia significativamente de acordo com a classe de solo. 
O efeito do tráfego dos tratores florestais sobre o solo é maior nas primeiras passadas, e o aumento na densidade do solo nas trilhas de tráfego está relacionado com o número de passadas, os tipos de rodado, o teor de matéria orgânica do solo e o tipo de máquina utilizada no sistema de colheita (SEIXAS, 2000). Segundo esse autor, os valores de densidades considerados prejudiciais estão em torno de 15 a $20 \%$ maiores que o valor inicial da densidade média do solo.

A influência do número de passadas dos rodados de um forwarder no nível de compactação de um solo, analisado segundo a sua densidade, ocorreu, conforme Fernandes et al. (1997), depois da primeira passada, voltando a acontecer após a nona. Esses autores observaram que o número de passadas não influenciou significativamente os valores de resistência do solo à penetração.

De acordo com Miranda (1986), os valores de resistência à penetração ao longo do perfil do solo, antes e depois do preparo, constituem um meio para verificar o grau de mobilização do solo, identificar camadas adensadas, determinar a eficiência de equipamentos e avaliar o potencial para o desenvolvimento de raízes.

Lima et al. (2001) avaliaram o comportamento da resistência do solo à penetração em trilhas entre linhas de plantio de eucalipto, em função da profundidade e do teor de água no solo. O sistema de colheita avaliado foi composto de um trator florestal derrubadoramontoador feller bunche de pneus com estrutura diagonal e de um trator florestal arrastador skidder, com pneus de baixa pressão. Segundo esses autores, a resistência do solo à penetração variou após o tráfego das máquinas, e a variação mais acentuada ocorreu na profundidade entre $0-10 \mathrm{~cm}$, crescente com o aumento da profundidade.

Dias Júnior e Pierce (1996) consideraram que as operações motomecanizadas utilizadas na colheita causaram prejuízos ao desenvolvimento das plantas, pelo fato de provavelmente não haver controle rígido do teor de água do solo ou capacidade de suporte de carga no momento das operações. Para esses autores, o teor de água no momento em que o solo está sendo compactado tem grande influência na redução e redistribuição do espaço poroso. Os solos com baixos teores de água têm maior resistência à compactação. Seixas (2000) afirmou que os efeitos do conteúdo de água se alteram com as características do solo e o esforço de compactação aplicado sobre este. Se o teor de água aumenta, a resistência à compactação diminui, devido à maior lubrificação entre as partículas do solo.

Diante do exposto e mediante a importância do setor florestal para a economia do país e, ainda, a escassez de pesquisas no Brasil que tratam da influência da compactação do solo no desenvolvimento florestal e na rebrota, assim como de sua correlação com o sistema de colheita florestal, considerados parâmetros importantes para um manejo adequado das condições físicas do solo, melhorando a produtividade da floresta e atendendo às exigências ambientais, este trabalho procurou avaliar os níveis de compactação do solo causados por dois tipos de máquinas de arraste de madeira (tracked skidder e clambunk) em um solo submetido a essa modalidade de baldeio em floresta de eucaliptos.

\section{MATERIAL E MÉTODOS}

Este trabalho foi conduzido em áreas de operações florestais de colheita em povoamento de eucaliptos, pertencente à Celulose Nipo-Brasileira-Cenibra, localizada no Município de Belo Oriente, no Estado de Minas Gerais.

As áreas em que foram efetuadas as coletas de dados são caracterizadas por uma topografia entre 12 e $35 \%$ de declividade, altitudes variando entre 600 e $800 \mathrm{~m}$, latitude sul de $19^{\circ} 22^{\prime} 17^{\prime}$ ' e longitude oeste de $42^{\circ} 28^{\prime} 18^{\prime}$, , clima subtropical úmido e precipitação média anual de $1.200 \mathrm{~mm}$. O solo da região foi classificado como um Latossolo Vermelho-Amarelo, textura argilosa.

O experimento foi conduzido utilizando dois tipos de máquinas: um trator arrastador clambunk da Timberjack modelo 1710, com esteiras metálicas nos rodados de pneus, potência de $156,7 \mathrm{~kW}$, massa de $20,8 \mathrm{kN}$, equipado com lâmina frontal tipo bulldozer (Figura 1) e trator arrastador da Caterpilar com esteiras metálicas tracked-skidder, modelo 527, potência de 112 kW e massa de $21,5 \mathrm{kN}$ equipado com lâmina frontal tipo bulldozer, arco acumulador da marca ESCO, com área útil de $0,93 \mathrm{~m}^{2}$, montado com braço articulado swing boom (Figura 2).

R. Árvore, Viçosa-MG, v.30, n.3, p.369-376, 2006 




Figura 1 - Trator arrastador de pneus.

Figure 1-Clambunk.

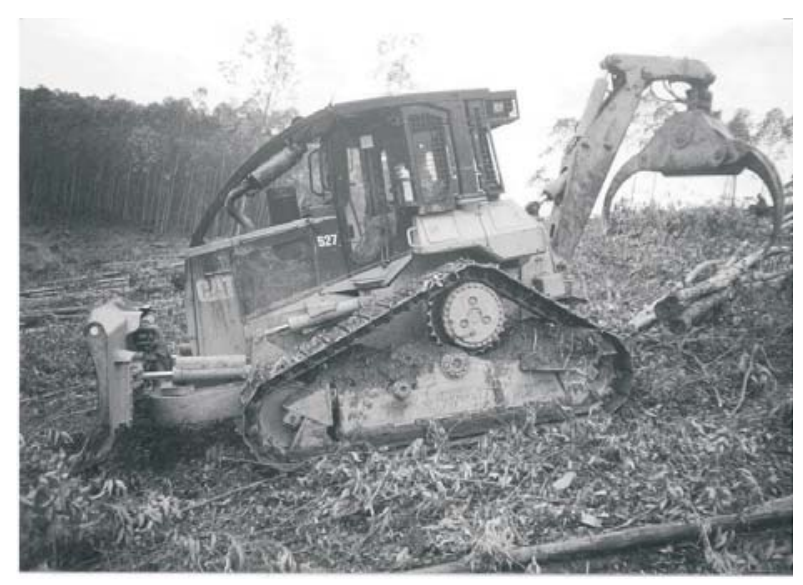

Figura 2 - Trator arrastador de esteiras.

Figure 2-Tracked skidder.

Para seleção e demarcação dos locais de avaliação, sortearam-se antecipadamente as trilhas, relacionando o número de percursos (sem carga, um e dois percursos com carga) com o tipo de máquina. Os tratamentos foram definidos conforme a seguir:

TS. $\mathrm{V}=$ tracked skidder sem carga; $\mathrm{TS} . \mathrm{C} 1=$ tracked skidder com carga em um percurso; TS.C2 = tracked skidder com carga em dois percursos; $\mathrm{CL}$. V = clambunk sem carga; CL.C1 = clambunk com carga, em um percurso; CL.C2 = clambunk com carga, em dois percursos; e TEST $=$ testemunha (trilha de sem tráfego).

Para análise da densidade do solo foram coletadas amostras indeformadas por meio do método do anel volumétrico de Uhland em três níveis de profundidade do perfil do solo: $0-15 \mathrm{~cm} ; 15-30 \mathrm{~cm}$; e $30-50 \mathrm{~cm}$, em quatro pontos espaçados de $10 \mathrm{~m}$ entre si e distribuídos ao longo da trilha. Após a coleta, as amostras foram colocadas em estufa durante 24 horas, a $105^{\circ} \mathrm{C}$.

A densidade do solo foi determinada utilizando a seguinte expressão:

$$
D S=\frac{M S}{V A}
$$

eq. 1

em que:

DS = densidade do solo $\left(\right.$ g. $\left.\mathrm{cm}^{-3}\right)$;

MS = massa do solo secado em estufa a $105^{\circ} \mathrm{C}$; e

$\mathrm{VA}=$ volume do anel $\left(\mathrm{cm}^{3}\right)$.

A porosidade foi determinada pelo método indireto:

$$
P O T=\left(1-\frac{D S}{D P}\right) \times 100
$$

eq. 2

em que:

$$
\begin{aligned}
& \text { POT = porosidade total }(\%) \\
& \text { DS = densidade do solo }\left(\mathrm{g} \mathrm{cm}^{-3}\right) ; \mathrm{e} \\
& \text { DP = densidade das partículas }\left(\mathrm{g} \mathrm{cm}^{-3}\right) .
\end{aligned}
$$

A densidade das partículas foi determinada pelo método do balão volumétrico, proposto por Kihel (1979).

A resistência do solo à penetração foi determinada através de um penetrógrafo marca Soil Control, modelo SC-60, com uma haste de $600 \mathrm{~mm}$ de comprimento, 9,53 mm de diâmetro, equipada com um cone de 129,3 mm² de área da base, 12,83 mm de diâmetro e 30 graus de ângulo sólido. Foram determinados valores em quatro pontos, espaçados ao longo da trilha e discutidos em três níveis de profundidade. A resistência mecânica do solo à penetração foi expressa através do índice de cone (IC), nos intervalos de $0-15 \mathrm{~cm}, 15-30$ $\mathrm{cm}$ e $30-50 \mathrm{~cm}$ para cada tratamento, conforme metodologia da ASAES 313, citada por Balastreire (1987).

O conteúdo de água no solo foi determinado através do método gravimétrico, obtido pela relação entre a massa de água e a massa de solo da amostra secada em estufa a $105^{\circ} \mathrm{C}$, por 24 horas.

Para análise de variância dos resultados, utilizouse o delineamento estatístico em blocos casualizados em esquema fatorial $2 \times 3 \times 3$, sendo duas máquinas e três condições de tráfego e um tratamento adicional 
como controle, com quatro repetições. O estudo foi realizado em três níveis de profundidade, $0-15 \mathrm{~cm}$, $15-30 \mathrm{~cm}$ e $30-50 \mathrm{~cm}$. Utilizando-se o programa estatístico SAEG, versão 8.0, os dados referentes aos teores de água foram submetidos às análises de variância e as médias, comparadas pelo teste de Tukey a 5\% de significância. Os demais dados foram submetidos ao teste de Dunnett a 5\% de significância, para comparar os tratamentos entre si. Cada bloco foi demarcado em uma área de 0,25 ha, sendo $50 \mathrm{~m}$ de comprimento e $50 \mathrm{~m}$ de largura.

\section{RESULTADOS E DISCUSSÃO}

No Quadro 1 são apresentados os valores de conteúdo de água do solo nas três profundidades estudadas, em que os resultados indicaram que os valores não apresentaram efeito significativo a $5 \%$.

Os valores de densidade do solo nas profundidades analisadas não registraram interação significativa nos fatores máquinas e condição de tráfego. Os efeitos causados pelo tráfego das máquinas foram evidenciados quando se compararam os tratamentos com a testemunha, conforme Quadro 2.

Na profundidade superficial do solo $(0-15 \mathrm{~cm})$, apenas o TS.V não registrou efeito significativo para valores de densidade do solo. Para $15-30 \mathrm{~cm}$ de profundidade, o trator arrastador do tipo clambunk com carregamento em um ou dois percursos interferiu na densidade do solo em relação à testemunha, sendo duas passadas a operação de maior impacto. Na profundidade de $30-50 \mathrm{~cm}$, os tratamentos TS.C1, CL.V e CL.C1 não afetaram significativamente a densidade do solo.

As Figuras 3, 4 e 5 representam o comportamento da densidade do solo em comparação com a testemunha, analisado pelo teste de Dunnet a 5\% de significância.

A maioria dos valores de porosidade do solo avaliado na profundidade entre $0-15 \mathrm{~cm}$ apresentou diferenças significativas, em comparação com os tratamentos com a testemunha (Figura 6).

Apenas o tratamento com tracked skidder trafegando sem carregamento não teve efeito sobre a porosidade do solo em relação à testemunha. $\mathrm{Na}$ profundidade entre $15-30 \mathrm{~cm}$ (Figura 7) não houve interação entre os fatores em estudo. Quando comparados com a testemunha, apenas o tratamento CL.C2 diferiu estatisticamente.

A Figura 8 ilustra que os tratamentos TS.C2 e CL.C2, que diferiram estatisticamente da testemunha, apresentando índices de porosidade do solo semelhantes aos encontrados por Seixas (2000). Esses índices acarretam danos ao sistema radicular do eucalipto.

Quadro 1 - Valores médios de conteúdo de água do solo nos três níveis de profundidade estudados Table 1 - Mean soil moisture in the three evaluated depths

\begin{tabular}{ccccccccc}
\hline Profundidade $(\mathrm{cm})$ & \multicolumn{9}{c}{ Tratamentos } \\
\cline { 2 - 7 } & TS.V & TS.C1 & TS.C2 & CL.V & CL.C1 & CL.C2 \\
\hline $0-15$ & $32,2 \mathrm{a}$ & $31,0 \mathrm{a}$ & $31,7 \mathrm{a}$ & $32,5 \mathrm{a}$ & $31,5 \mathrm{a}$ & $30,5 \mathrm{a}$ & $33,0 \mathrm{a}$ \\
$15-30$ & $29,75 \mathrm{a}$ & $29,5 \mathrm{a}$ & $29,4 \mathrm{a}$ & $30,0 \mathrm{a}$ & $29,75 \mathrm{a}$ & $30,25 \mathrm{a}$ & $30,25 \mathrm{a}$ \\
$30-50$ & $28,5 \mathrm{a}$ & $28,4 \mathrm{a}$ & $28,77 \mathrm{a}$ & $28,87 \mathrm{a}$ & $28,36 \mathrm{a}$ & $29,75 \mathrm{a}$ & $29,75 \mathrm{a}$ \\
\hline
\end{tabular}

Médias seguidas de pelo menos uma mesma letra dentro das linhas não diferem entre si pelo teste de Tukey $(\mathrm{P}<0,05)$.

Quadro 2 - Análise de variância dos valores de densidade do solo na profundidade de $15-30 \mathrm{~cm}$ Table 2-Analysis of variance of soil dry bulk density at 15-30 cm depth

\begin{tabular}{|c|c|c|c|c|c|}
\hline Fontes de Variação & GL & Soma de Quadrado & Quadrado Médio & $\mathrm{F}$ & Sig. \\
\hline Máq. (M) & 1 & 0,0054 & 0,0054 & 1,25 & ns \\
\hline Cond. (C) & 2 & 0,0256334 & 0,0128167 & 2.96 & ns \\
\hline $\mathrm{M}^{*} \mathrm{C}$ & 2 & 0,0061 & 0,00305 & 0,70 & ns \\
\hline Fat $v s$ Test & 1 & 0,0224023 & 0,0224 & 5,18 & $*$ \\
\hline Bloco & 3 & 0,03707 & 0,01235 & 2,86 & ns \\
\hline Residuo & 18 & 0,0778 & 0,00432 & & \\
\hline Total & 27 & 0,1744 & & & \\
\hline
\end{tabular}




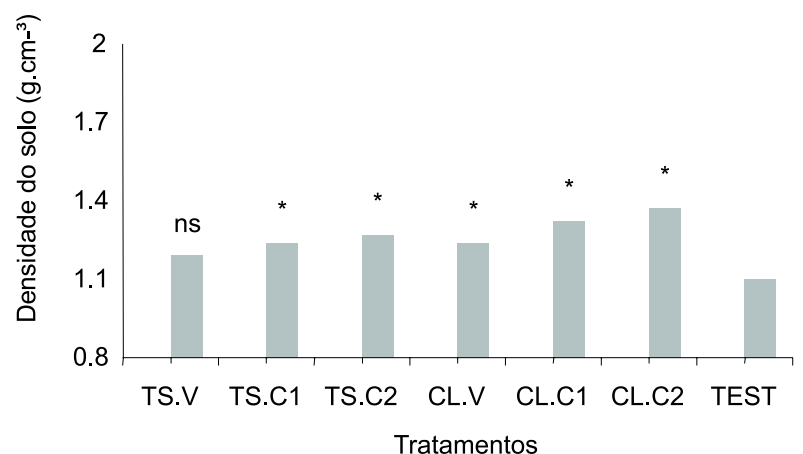

Figura 3 - Representação dos valores médios de densidade do solo na profundidade entre $0-15 \mathrm{~cm}(\mathrm{~ns})$, em comparação com a testemunha. Não-significativo ou (*) significativamente diferente da testemunha, pelo teste de Dunnett a 5\% de significância.

Figure 3 - Mean soil dry bulk density at $0-15 \mathrm{~cm}$ depth. (ns) in comparison to control. Non-significant and (*) significantly different from the control by the Dunnett test, $p<0.05$.

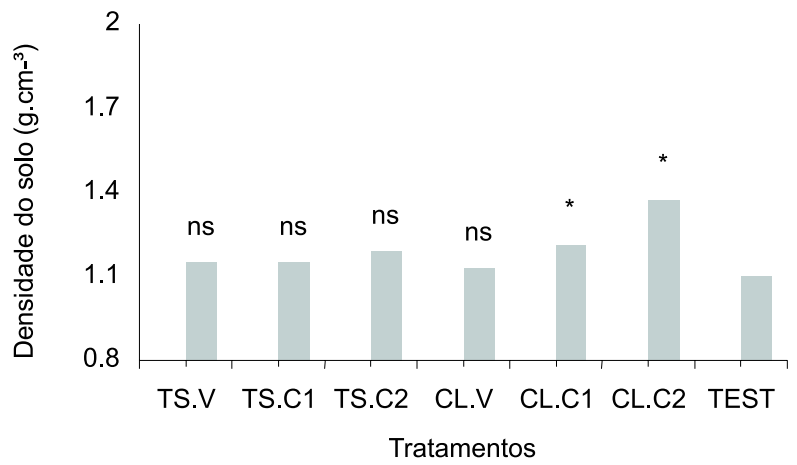

Figura 4 - Representação dos valores médios de densidade do solo na profundidade entre $15-30 \mathrm{~cm}(\mathrm{~ns})$, em comparação com a testemunha. Não-significativo ou (*) significativamente diferente da testemunha, pelo teste de Dunnett a 5\% de significância.

Figure 4-Mean soil dry bulk density at $15-30 \mathrm{~cm}$ depth. (ns) in comparison to control. Non-significant and (*) significantly different from the control by the Dunnett test, $p<0.05$.

Os valores de resistência do solo à penetração na profundidade entre $0-15 \mathrm{~cm}$ são apresentados na Figura 9.

O tracked skidder com dois percursos com carga e o clambunk com um e dois percursos com carga

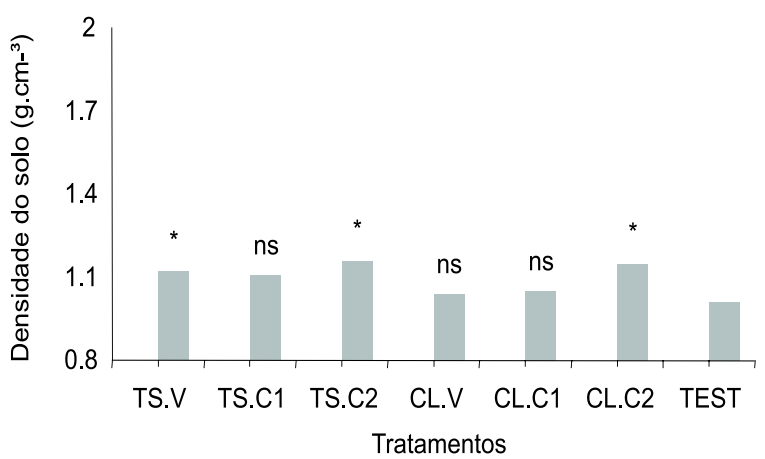

Figura 5 - Representação dos valores médios de densidade do solo na profundidade entre $30-50 \mathrm{~cm}(\mathrm{~ns})$, em comparação com a testemunha. Não-significativo ou (*) significativamente diferente da testemunha, pelo teste de Dunnett a 5\% de significância.

Figure 5-Mean soil dry bulk density at $30-50 \mathrm{~cm}$ depth $(n s)$ in comparison to control. Non-significant and $(*)$ significantly different from the control by the Dunnett test, $p<0.05$.

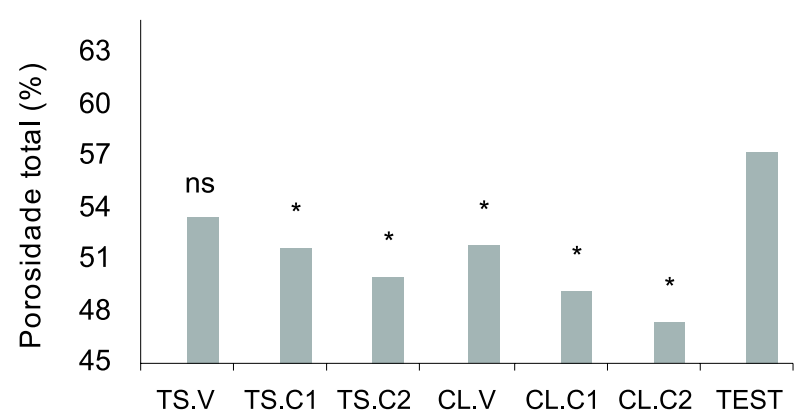

Figura 6 - Representações dos valores médios de porosidade do solo na profundidade entre $0 \mathrm{~cm}-15 \mathrm{~cm}(\mathrm{~ns})$, em comparação com a testemunha. Não-significativo ou (*) significativamente diferente da testemunha, pelo teste de Dunnett a 5\% de significância.

Figure 6 - Soil total porosity at $(0-15 \mathrm{~cm})$ depth $(\mathrm{ns})$ in comparison to control. Non- significant and $(*)$ significantly different from the control by the Dunnett test, $p<0.05$.

registraram efeitos significativos na resistência do solo à penetração. Nas Figuras 10 e 11, mostra-se que, na profundidade entre $15-50 \mathrm{~cm}$, apenas o clambunk trafegando duas vezes registrou efeito significativo sobre a resistência do solo à penetração. 


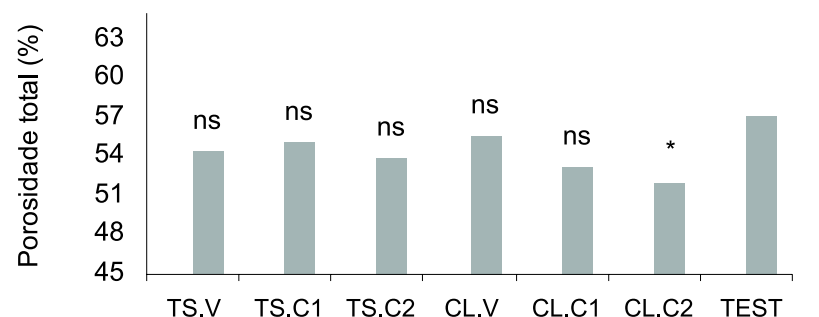

Figura 7 - Representações dos valores médios de porosidade do solo na profundidade de $15-30 \mathrm{~cm}$ (ns), em comparação com a testemunha. Não-significativo ou (*) significativamente diferente da testemunha, pelo teste de Dunnett a 5\% de significância.

Figure 7 -Soil total porosity at $(15-30 \mathrm{~cm})$ depth. ( $\mathrm{ns})$ in comparison to control. Non- significant and (*) significantly different from the control by the Dunnett test, $p<0.05$.

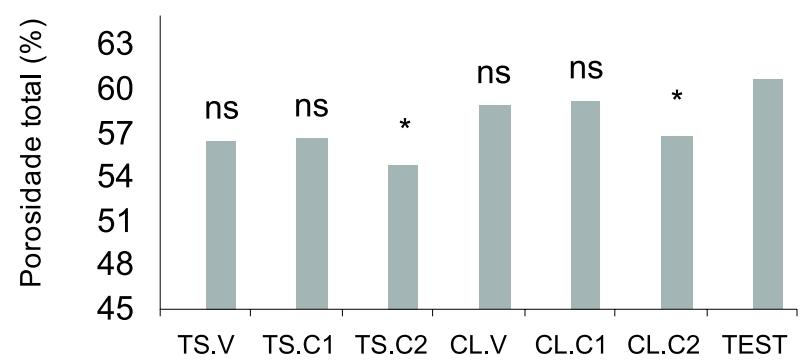

Figura 8 - Representações dos valores médios de porosidade do solo na profundidade de $30-50 \mathrm{~cm}$, em comparação com a testemunha (ns). Não-significativo ou (*) significativamente diferente da testemunha, pelo teste de Dunnett a 5\% de significância.

Figure 8 -Soil total porosity at $(30-50 \mathrm{~cm})$ depth. ( $\mathrm{ns})$ in comparison to control. Non- significant and (*) significantly different from the control by the Dunnett test, $p<0.05$.

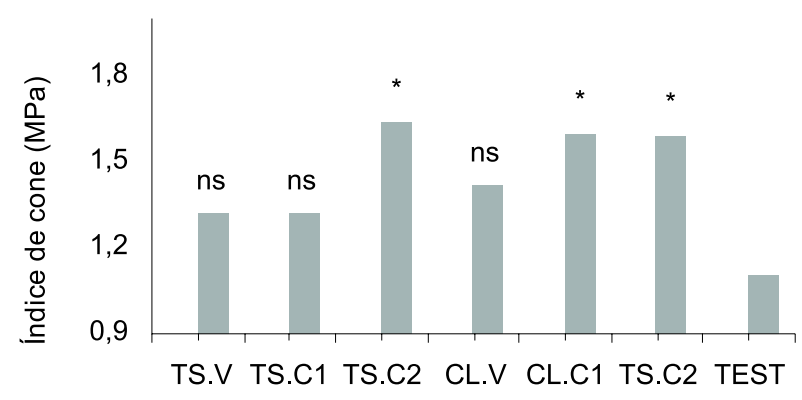

Figura 9 - Valores de resistência à penetração na profundidade entre $0-15 \mathrm{~cm}$, em comparação com a testemunha.

Figure 9 - Values of soil penetrometer resistance at 0-15 cm depth in comparison to control.

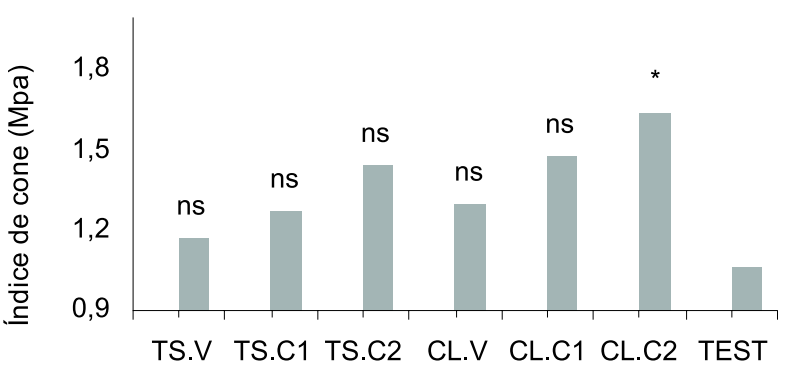

Figura 10 - Valores de resistência à penetração na profundidade entre 15-30 cm, em comparação com a testemunha.

Figure 10 - Values of soil penetrometer resistance at 15$30 \mathrm{~cm}$ depth in comparison to control.

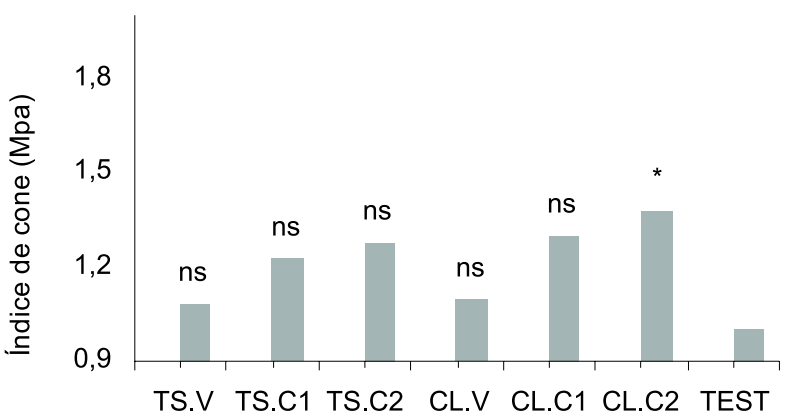

Figura 11 - Valores de resistência à penetração na profundidade entre 30-50 cm, em comparação com a testemunha.

Figure 11 - Values of soil penetrometer resistance at 30 $50 \mathrm{~cm}$ depth in comparison to control.

\section{CONCLUSÕES}

O tracked skider sem carregamento não interferiu no aumento da densidade do solo, à exceção da profundidade entre $30-50 \mathrm{~cm}$. Ocorreu efeito em relação à profundidade entre $0-15 \mathrm{~cm}$ do solo em ambas as condições, quando se trafegou com carregamento.

O trator florestal arrastador do tipo clambunk afetou a densidade do solo na profundidade entre $0-15 \mathrm{~cm}$, em todas as condições de tráfego. Foram verificados valores mais elevados quando a máquina trafegou por uma e duas vezes com carregamento, sendo dois percursos a condição que mais afetou a densidade do solo.

Os maiores valores da porosidade foram registrados à profundidade de $0-15 \mathrm{~cm}$.

Ambas as máquinas, quando trafegaram carregadas, registraram maiores incrementos nos valores da resistência do solo à penetração.

R. Árvore, Viçosa-MG, v.30, n.3, p.369-376, 2006 


\section{REFERÊNCIAS BIBLIOGRÁFICAS}

\section{ASSOCIAÇÃO BRASILEIRA DE NORMAS}

TÉCNICAS - ABNT. Solo - análise

granulométrica: norma NBR 7181. Rio de

Janeiro: 1982. 16p.

BALASTREIRE, L. A. Máquinas agrícolas. São Paulo: Manole, 1987. 307p.

CAMARGO, O.A. Compactação do solo e desenvolvimento de plantas. Campinas: Fundação Cargil, 1983. 44p.

DIAS JÚNIOR, M. S. Avaliação quantitativa da sustentabilidade estrutural de um Latossolo Vermelho Amarelo situado em áreas experimentais da Cenibra. Lavras: UFLA, 1999. 23p. (Relatório do Projeto de Pesquisa).

DIAS JÚNIOR, M. S.; PIERCE, F.J. O processo de compactação do solo e sua modelagem. Revisão de Literatura. R. Bras. Ci. Solo, v. 20, p. 175-182, 1996.

FERNANDES, H.C.; ORLANDO, R,C.; LANÇAS, K.P. Compactação do solo em relação à exploração florestal: influência do "forwarder" e do "harvester". Engenharia na Agricultura, v. 5 , n. 4 , p. 276 - $280,1997$.

GREACEN, E.L.; SANDS, R. Compaction of forest soils a review. Gleis Osmond: Australian Journal of Soil Research, v. 18 , n. 2, p. 163-89,1980.
HASSAN, A. E.; SIROIS, D. L. Transaction and roling resistance of a dual-tired skidder on wetland.Transaction of the ASAE, v. 28, n. 5 , p. $1038-1042,1985$.

KIHEL, E. J. Manual de edafologia. São Paulo: Ceres, 1979. 263p.

KONDO, M.K.; DIAS JÚNIOR, M.S.

Compressibilidade de três Latossolos em função da umidade e uso. Revista Brasileira de Ciência do Solo, v. 23, n. 2, p. 211-218, 1999.

LIMA, J.S.S.et al. Estudo do comportamento da resistência do solo à penetração em trilha de tráfego na colheita de madeira. In: SIMPÓSIO BRASILEIRO DE SOBRE COLHEITAE TRANSPORTE DE MADEIRA FLORESTAL, 5., 2001, Porto Seguro. Anais... Viçosa, MG: SIF, 2001. p. 281-289.

MIRANDA, N. O. Alterações físicas nos solos podzólicos vermelho escuro submetidos a diferentes condições de preparo reduzido. 1986. 64f. Dissertação (Mestrado em Engenharia Agrícola) - Universidade Federal de Santa Maria, Santa Maria, 1986.

SEIXAS, F. Compactação do solo devido à colheita de madeira. 2000, 75f. Tese (Livre Docência) - Escola Superior de Agricultura Luiz de Queiroz, Piracicaba, 2000.

SEIXAS, F.Compactação do solo devido a mecanização florestal. Piracicaba: IPEF, 1988. 10p. (Circular Técnica, 163). 